\title{
The Study of Natural Gas Hydrates Decomposition Conditions in Order to Determine Their Possible Influence on Gasodynamic Processes
}

\author{
Tatyana Kim \\ Department of Physics \\ T. F. Gorbachev Kuzbass State \\ Technical University \\ Kemerovo, Russia \\ email: ktl.fiz@kuzstu.ru
}

\author{
Valery Dyrdyn \\ Department of Physics \\ T. F. Gorbachev Kuzbass State \\ Technical University \\ Kemerovo, Russia \\ email:vvd1941@live.ru
}

\author{
Vyacheslav Smirnov \\ Department of Physics \\ T. F. Gorbachev Kuzbass State \\ Technical University \\ Kemerovo, Russia \\ email: smirnovvg@mail.ru
}

\begin{abstract}
The conditions of natural gas hydrates formation were studied experimentally. The composition of natural gas was determined chromatographically. The equilibrium points of the natural gas hydrate on the P-T diagram are determined. It was found that the point of natural gas hydrate formation is always below the equilibrium curve of methane hydrate. In the band of positive temperatures of coal seams, the decomposition of natural gas hydrates creates an additional amount of gas, which can affect the formation of outburst hazard situations in the marginal zone of coal seams.
\end{abstract}

Keywords-- natural gas hydrate, coal seam, methane, equilibrium curve

\section{INTRODUCTION}

Underground mining of coal seams is complicated by various gas-dynamic activities, including sudden coal and gas outburst. In the formation of outburst hazard situations, one of the key roles may be played by the decomposition of gas hydrates that were formed either during the metamorphism of coal seams, or when the corresponding thermobaric conditions occurred.

The coal seam is a multicomponent system that includes a solid substance of coal, a mixture of gases called the coal bed gas, as well as water and aqueous solutions. During the metamorphism of coal, the main components of the coal seams gases were formed: methane, carbon dioxide, and light hydrocarbons.

The natural gas in a coal seam is in a free, sorbed state and in the form of a solid coal-gas solution, as well as in the form of gas hydrates. Professor Ayruni A. T. notes the following quantitative ratios of different forms of methane presented in the coal seam[1]: 70-85 \% - a solid carbonmethane solution that is in the intermolecular space of the coal substance; up to $10 \%$ of the gas - in a free state; $16 \%$ in adsorbed; $1-2 \%$ - chemically sorbed methane.

Natural gas in coal seams, as is shown by chromatographic studies, is a mixture of hydrocarbons: methane, propane, ethane and some non-hydrocarbon components such as hydrogen sulfide, nitrogen, carbon dioxide, water, etc. Almost all the components of natural gas can form hydrates mixing with water. Necessary conditions for gas hydrates formation are favorable thermobaric conditions, hydrate-forming substance and presence of water.

In J. Carroll's monograph "Hydrates of Natural Gas"[2], the issues related to the formation of hydrates of certain gases and their mixtures are discussed in detail. Computer methods for calculating hydrate formation conditions based on such well-known mathematical models as Van der Waals and Platteus model, Parrish model, Prausnitz model and Ng and Robinson model are presented.

The authors of [3-5] studied the formation of gas hydrates at high pressures. Hydrate formation processes in the terms of their influence on the formation of outburst hazard situations in coal seams in case of micro- and macrodisruptions ahead of the faces of the cleaning and preparatory excavations have recently caused much interest. It is clear that classical approaches to this problem do not remain without attention, either. The emergence of sudden emissions of coal and gas is determined by many factors, so, in [6], the effect of filtration and desorption processes on the initial conditions for the sudden emission of coal and gas was analyzed. A number of experiments were carried out with coal briquettes and three different gases (methane, carbon dioxide and nitrogen). Essential is not only the amount of gas emitted during the decomposition of gas hydrates, but also the equilibrium pressure and temperature at which the process of decomposition of hydrates begins.

Studies of the formation and decomposition of gas hydrates in porous media are being done both in our country and abroad [7, 8]. In addition to the formation of hydrates from free gas, the possibility of formation of gas hydrates from dissolved gas has been experimentally proved and the cementing properties of hydrates have been established.

The dissociation conditions of hydrates of methane, carbon dioxide and their mixtures in three model porous media at pressures less than $20 \mathrm{MPa}$ are described in [9]. Earlier, the authors of this work carried out experiments on the formation and decomposition of methane gas hydrates in a matrix of coals of various degrees of metamorphism [1013]. The possibility of the influence of natural gas hydrates on the mechanism of sudden outburst of coal and gas, as well as the way of mine workings gas contamination, was proved. The method of mathematical modeling was used to find the distribution of gas pressure ahead of the face of the preparatory workings [14].

In this article, the conditions for the formation of hydrates from water and natural gas in a free medium are studied. It is generally accepted that the thermobaric 
conditions for the formation of methane hydrates in coal seams are quite "rigid", since not always the gas pressure in coal seams reaches values greater than or equal to the equilibrium ones for the formation of methane hydrate at the bedding temperature. When mechanically destroying certain zones of a coal seam by the forces of rock pressure, the composition of the coal gases in these zones changes [15]. The coal bed contains $85-95 \%$ methane, as well as carbon dioxide, nitrogen, and other gases, so that the composition of the gas changes the thermobaric conditions of hydrate formation in a certain way.

It was shown experimentally in [16] that the thermodynamic conditions for the formation and decomposition of pure methane gas hydrates in coal samples taken from outburst-hazard coal seams of Kuzbass deviate less than $1{ }^{\circ} \mathrm{C}$ from the equilibrium curve of methane hydrates decomposition.

\section{MATERIALS AND METHODS}

The formation and decomposition of natural gas hydrates occurred in a high-pressure steel autoclave. Natural gas was used as a hydrate generator, its composition was determined by chromatographic studies. The concentration of methane in natural gas was $84.7 \%$, nitrogen $-7.1 \%$, oxygen $-2.5 \%$, other components - $5.8 \%$. The analysis was carried out at the Institute of Coal Chemistry and Material Science of Federal Research Center of Coal and Coal Chemistry SB RAS.

Stainless steel strips were placed in $300 \mathrm{ml}$ autoclave. Then, $62.6 \mathrm{~g}$ of distilled water were added and the autoclave was pumped with natural gas at the pressure of 7-10 MPa, the air having been replaced with natural gas before. Then the filled autoclave was kept at the temperature of $-5^{\circ}-$ $3{ }^{\circ} \mathrm{C}$ for 12 hours.

At the main stage of the experiment, the autoclave was in a liquid coolant thermostat. The temperature coolant outside the autoclave was set with a temperature programming unit. The temperature and gas pressure inside the autoclave were registered by sensors, all the data every 9 seconds being recorded on the computer using an analog-to-digital converter MIT8. The main part of the experiment was the investigation of the reaction of the created water - natural gas - natural gas hydrate system to a slow rise in temperature.

The experiments were carried out at the temperatures from $-5{ }^{\circ} \mathrm{C}$ to $+25{ }^{\circ} \mathrm{C}$, at heating rates of 1.0 or $2.0 \mathrm{~K} / \mathrm{h}$. The linear increase in the temperature of the coolant led to a linear increase in the temperature and pressure of the inner chamber of the autoclave. The decomposition of the gas hydrate was expressed in the step of increasing the pressure in the experimental pressure-temperature diagram (fig. 2). The temperature and pressure in the autoclave at the beginning of the pressure increase step correspond to the temperature and pressure of decomposition the natural gas hydrate. The chromatogram of the investigated natural gas is shown in Fig. 1.

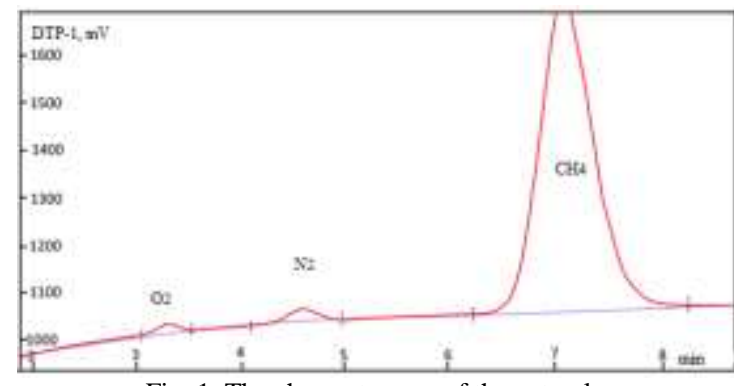

Fig. 1. The chromatogram of the natural gas

Three experiments were conducted on the formation and decomposition of natural gas hydrate, which allowed to obtain temperature - pressure points of decomposition of natural gas hydrate in the region of positive temperatures.

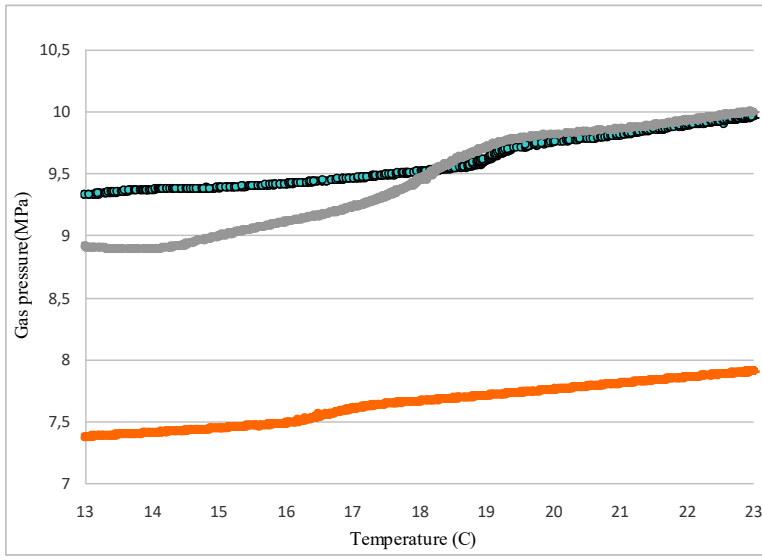

Fig.2. The experimental curves of the P-T diagram (processes № 1, 2, 3)

The decomposition of the gas hydrate is accompanied by additional gas emission, which is expressed in an increase in the gas pressure in the autoclave. Characteristic jumps in gas pressure caused by the decomposition of natural gas hydrate can be seen in Fig.2. The processes shown in Fig. 2 are presented in other scales in Fig. 2.1.-2.3 for visual clarity. In Fig. 2.1 they are recorded at $\mathrm{T}=18.8^{\circ} \mathrm{C}$ and $\mathrm{p}=9.5 \mathrm{MPa}$. This is the experimental point of natural gas hydrate decomposition.

The same gas pressure jumps due to the decomposition of the formed gas hydrate were obtained by repeated experiments with natural gas. In Fig. 2.2. pressure jump was recorded at $\mathrm{T}=16.3^{\circ} \mathrm{C} ; \mathrm{p}=7.45 \mathrm{MPa}$. And in Fig. 2.3 at $\mathrm{T}$ $=17.2^{\circ} \mathrm{C}$ and $\mathrm{p}=8.9 \mathrm{MPa}$.

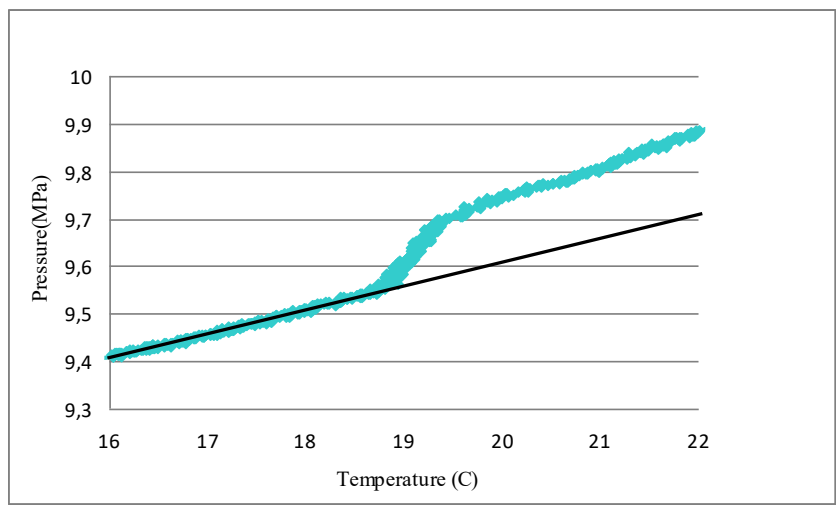

Fig. 2.1. Experimental P-T diagram of the process №1 


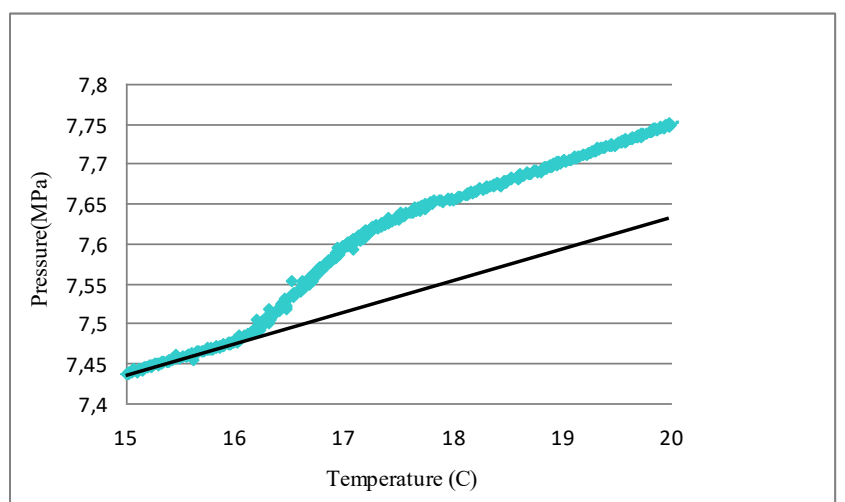

Fig. 2.2. Experimental P-T diagram of the process №2

The experimental points of the equilibrium curve of the decomposition of natural gas hydrate at different rates of temperature change are shown in Fig. 3.

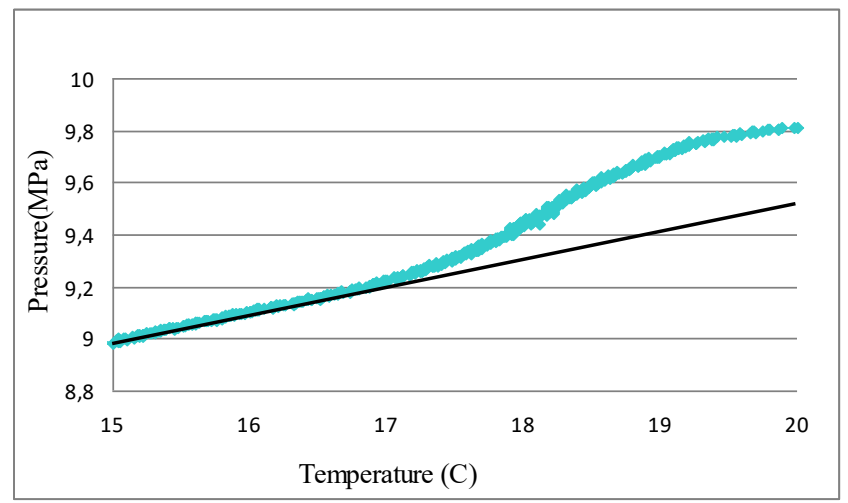

Fig. 2.3. Experimental P-T diagram of process №3

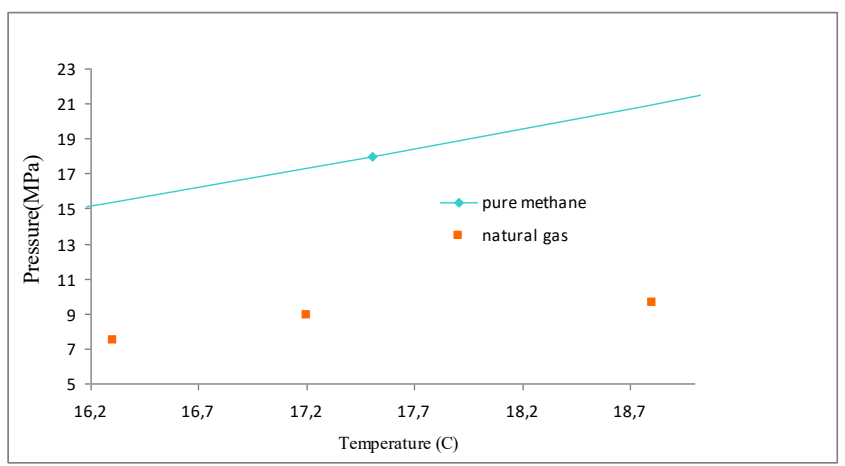

Fig. 3. Equilibrium curves of methane hydrate and point of natural gas hydrate decomposition

\section{DISCUSSION}

On the basis of the data obtained during the experiments, a points of natural gas hydrate decomposition were determined (Fig. 3), and according to the data of [2] the equilibrium curve for pure methane (upper curve) was also built. As can be seen from the experiments carried out, decomposition of natural gas hydrate occurs at considerably lower gas pressures compared to the equilibrium curve of methane hydrate. Consequently, the conditions for the formation and decomposition of natural gas hydrates are much "softer" than for pure methane, the pressure range is 7.5-12 $\mathrm{MPa}$ at the same decomposition temperatures of about (15-18) ${ }^{\circ} \mathrm{C}$.

The conditions of hydrate formation of natural gas correspond to thermodynamic and mining-geological conditions of coal seams bedding of Kuzbass, which are dangerous for sudden outbursts of coal and gas.

\section{CONCLUSIONS}

1) the equilibrium pressure of natural gas hydrate decomposition is always much lower than the equilibrium curve of methane hydrate. An admixture of up to $15 \%$ in the composition of hydrocarbon components of natural gas makes it possible to soften the conditions for the formation and decomposition of gas hydrates by $30-40 \%$ in the region of positive temperatures $(15-18)^{\circ} \mathrm{C}$, corresponding to the conditions of bedding of outburst-hazard coal seams of Kuzbass;

2) the decomposition of natural gas hydrates creates an additional amount of free gas, leading to the formation of various gas-dynamic processes;

3) the technology of underground mining of coal seams should provide methods for detecting the accumulation of gas hydrates in coal seams in order to improve the safety of mining operations.

\section{REFERENCES}

[1] Ayruni A. T. Forecasting and prevention of gas-dynamic phenomena in coal mines. - Moscow: Science, 1987.

[2] Carroll Jon Hydrates of natural gas. Translation from English. Moscow: ZAO Premium Engineering, 2007.

[3] Dyadin Yu.A., Larionov E.G., Manakov A.Yu., Kurnosov A.V., Zhurko F.V., Aladko E. Ya., Ancharov A.I., Tolochko B.P., Sheromov M.A. A clathrate hydrates of sulfur hexafluoride at high pressures [J]. Journal of Inclusion Phenomena, 2002, 42(3-4): 213218 .

[4] Dyadin Yu. A., Guschin A. L. Gas hydrates [J]. Soros Educational Journal,1998, 3: 55-64.

[5] Dyrdin V. V., Smirnov V. G., Kim T. L., Manakov A. Yu., Fofanov A. A., Kartopolova I. S. Thermodynamic changes in the coal matrix gas - moisture system under pressure release and phase transformations of gas hydrates [J]. Russian Physics Journal, 2017, 60(2): 206-214.

[6] Sobczyk J. A comparison of the influence of adsorbed gases on gas stresses leading to coal and gas outburst. Fuel, 2014, 115: 288-294.

[7] Tohidi B., Anderson R., Clennel B., Burgass R. W., Biderkab A. B. Geology, 2001, v.29(29): 867-870.

[8] Tohidi B., Anderson R., Clennel B., Yang J., Bashir A., Burgass R. W In: Proc. Of the 4th Inc. Conf. On Gas Hydrate (ICGH4). Yokohama, Japan, 19-23 May (2002), p. 761-765.

[9] Anderson R., Llamedo M., Tohidi B. J. Phys. Chem. B, 2003, v. 107, p.3500-3506.

[10] [10] Kim T.L. Formation of Solid Solutions of Natural Gas in a Coal Matrix [J]. Bulletin of the Kuzbass State Technical University, 2013(6): 9-12.

[11] Kim T. L. The speed of moving the boundary of the dissociation of solid solutions of natural gas in a coal matrix. Sb. Theses and reports: All-Russian Youth Conference. Chemical physics and actual problems of power engineering: Tomsk Polytechnic University, 2012: $133-135$.

[12] Smirnov V. G., Dyrdin V.V., Ismagilov Z. R., Kim T. L. Influence of decomposition of gas hydrates on the growth of cracks in a coal massif ahead of the face of the preparatory workings. News of higher educational institutions. Izvestiya vysshikh uchebnykh zavedeniy. Gornyy zhurnal. 2016(3): 96-103.

[13] Smirnov V.G., Dyrdin V.V., Manakov A.Yu., Ismagilov Z.R., Adamova T.P. //Problem of pulverized coal formation at mine outburst caused by decomposition of gas hydrates in coal seams [J]. Chemistry for Sustainable Development. 2016, 24(4): 499-507. 
[14] Kim T. L., Dyrdin V.V., Belkov V. A. Mathematical modeling of the process of dissociation of crystalline hydrate in the marginal zone of a coal seam $[\mathrm{J}]$. Bulletin of the Kuzbass State Technical University, 2011(2): 19 - 21.

[15] Dyrdin V.V., Fofanov A. A., Kim T. L., Smirnov V. G., Tatsienko V. P., Kozlov A. A., Plotnikov E. A. Influence of Mechano-Degradation of Coal on Formation of Gas Dynamic Processes Under Underground
Coal Formation Development. Occupational safety in industry, 2017(8): 10-15.

[16] Smirnov V.G., Manakov A.Yu., Dyrdin V.V., Ismagilov Z.R. Studies of the formation and decomposition of methane hydrates in pores of natural coal $[\mathrm{J}]$. Bulletin of the Kuzbass State Technical University, 2014. No. 2 (102). Pp. 27-30. 